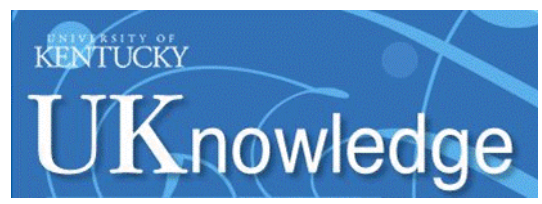

University of Kentucky

UKnowledge

$10-1-2018$

\title{
Translational Evaluation of Acid/Base and Electrolyte Alterations in Rodent Model of Focal Ischemia
}

\author{
Sarah R. Martha \\ University of Kentucky \\ Lisa A. Collier \\ University of Kentucky \\ Stephanie M. Davis \\ University of Kentucky, stephanie.davis@uky.edu \\ Hilary A. Seifert \\ Oregon Health \& Science University \\ Christopher C. Leonardo \\ University of Southern Florida \\ Sellowext this and fadditionahworks,at: https://uknowledge.uky.edu/neurology_facpub \\ Part of the Neurology Commons, Neurosciences Commons, Neurosurgery Commons, and the Nursing \\ Commons
}

Right click to open a feedback form in a new tab to let us know how this document benefits you.

\section{Repository Citation}

Martha, Sarah R.; Collier, Lisa A.; Davis, Stephanie M.; Seifert, Hilary A.; Leonardo, Christopher C.; Ajmo, Craig T.; Foran, Elspeth A.; Fraser, Justin F.; and Pennypacker, Keith R., "Translational Evaluation of Acid/ Base and Electrolyte Alterations in Rodent Model of Focal Ischemia" (2018). Neurology Faculty Publications. 69.

https://uknowledge.uky.edu/neurology_facpub/69

This Article is brought to you for free and open access by the Neurology at UKnowledge. It has been accepted for inclusion in Neurology Faculty Publications by an authorized administrator of UKnowledge. For more information, please contact UKnowledge@lsv.uky.edu. 


\section{Translational Evaluation of Acid/Base and Electrolyte Alterations in Rodent Model of Focal Ischemia}

\section{Digital Object Identifier (DOI)}

https://doi.org/10.1016/j.jstrokecerebrovasdis.2018.05.045

\section{Notes/Citation Information}

Published in Journal of Stroke and Cerebrovascular Diseases, v. 27, issue 10.

(c) 2018 Elsevier Ltd.

(c) 2018. This manuscript version is made available under the CC-BY-NC-ND 4.0 license

https://creativecommons.org/licenses/by-nc-nd/4.0/

\section{Authors}

Sarah R. Martha, Lisa A. Collier, Stephanie M. Davis, Hilary A. Seifert, Christopher C. Leonardo, Craig T. Ajmo, Elspeth A. Foran, Justin F. Fraser, and Keith R. Pennypacker 


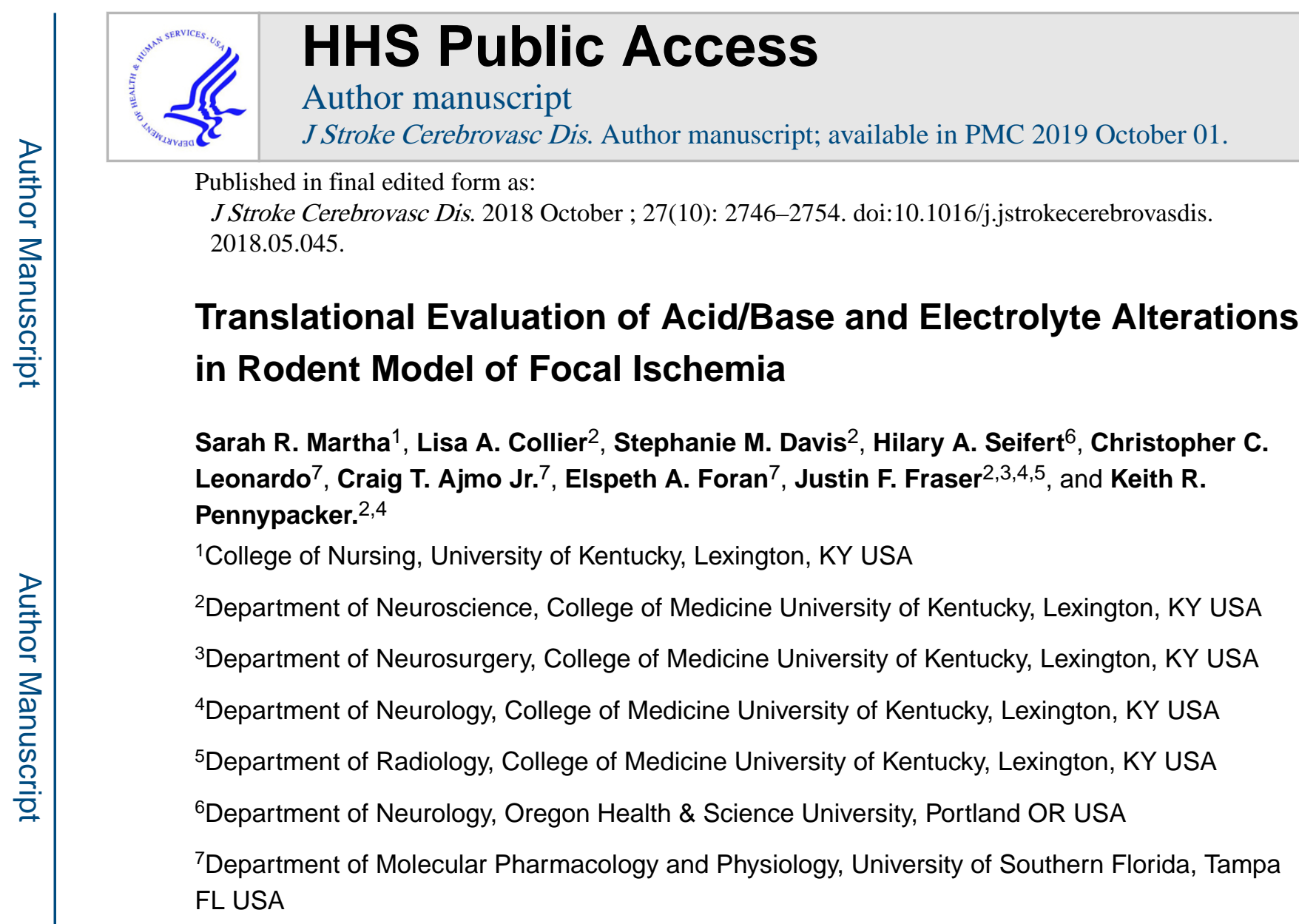

\section{Abstract}

Background and Purpose-Acid/base and electrolytes could provide clinically valuable information about cerebral infarct core and penumbra. We evaluated associations between acid/ base and electrolyte changes and outcomes in two rat models of stroke, permanent and transient middle cerebral artery occlusion.

Methods-Three-month old Sprague-Dawley rats underwent permanent or transient middle cerebral artery occlusion. Pre- and post-middle cerebral artery occlusion venous samples for permanent and transient models provided $\mathrm{pH}$, carbon dioxide, oxygen, glucose, and electrolyte values of ionized calcium, potassium and sodium. Multiple regression determined predictors of infarct volume from these values, and Kaplan-Meier curve analyzed morality between permanent and transient middle cerebral artery occlusion models.

Correspondence: Sarah Martha, University of Kentucky, Nursing, Center for Advanced Translational Stroke Science, BBSRB, 741 S. Limestone Street, B406, Lexington, KY, USA 40536, (503) 853-9544, sarah.martha@uky.edu.

Publisher's Disclaimer: This is a PDF file of an unedited manuscript that has been accepted for publication. As a service to our customers we are providing this early version of the manuscript. The manuscript will undergo copyediting, typesetting, and review of the resulting proof before it is published in its final citable form. Please note that during the production process errors may be discovered which could affect the content, and all legal disclaimers that apply to the journal pertain.

Author Contribution Statment:

All authors made a substantial and intellectual contribution to the work.

Disclosure/Conflict of Interest:

The authors do not have competing interests.

Supplementary Information:

No supplementary information. 
Results-Analysis indicated significant differences in the blood gas and electrolytes between pre- to post-middle cerebral artery occlusion. A decrease in $\mathrm{pH}$ and sodium with increases in carbon dioxide, potassium, ionized calcium, and glucose changes were found in both middle cerebral artery occlusion models; while hematocrit and hemoglobin were significant in the transient model. $\mathrm{pH}$ and ionized calcium were predictors of infarct volume in the permanent model, as changes in $\mathrm{pH}$ and ionized calcium decreased, infarct volume increased.

Conclusion-There are acute changes in acid/base balance and electrolytes during stroke in transient and permanent rodent models. Additionally, we found $\mathrm{pH}$ and ionized calcium changes predicted stroke volume in the permanent middle cerebral artery occlusion model. These preliminary findings are novel, and warrant further exploration in human conditions.

\section{Keywords}

focal ischemia; acid/base balance; electrolytes; early blood chemistry changes; infarct volume

\section{INTRODUCTION}

Approximately $87 \%$ of strokes are ischemic, and are characterized by blockage of blood flow in the brain from a thrombus or embolus. ${ }^{1}$ Neurological insult occurs immediately when the cerebral artery is occluded, as neural tissue is deprived of oxygenated blood, glucose, and other nutrients. ${ }^{2}$ The penumbra, the area surrounding the infarct, also includes tissue at risk of cell death, and will expand to adjacent areas if reperfusion does not occur. ${ }^{2}$ When there are instabilities in cerebral blood flow (CBF), disturbances in brain metabolism occur, causing shifts in water and ion concentrations. With decreasing CBF, the blood downstream of the occlusion undergoes biochemical changes. Disruption in blood flow reduces oxygen $\left(\mathrm{O}_{2}\right)$ and glucose, and leads adenosine triphosphate (ATP) to be mismatched with use and production. ${ }^{3}$ Cerebral ischemia occurs when cerebral $\mathrm{O}_{2}$ supply fails to meet cerebral metabolic demand. Reduction in $\mathrm{CBF}$ causes lactic acid and carbon dioxide $\left(\mathrm{CO}_{2}\right)$ accumulation. ${ }^{4-6}$ Furthermore, electrolyte concentrations such as sodium $\left(\mathrm{Na}^{+}\right)$, calcium $\left(\mathrm{Ca}^{2+}\right)$ and potassium $\left(\mathrm{K}^{+}\right)$are sensitive to $\mathrm{pH}$ changes to maintain cellular structure and function. ${ }^{3}$ Dysregulation is additive, as disruption of the $\mathrm{Na}^{+} / \mathrm{Ca}^{2+}$ pump leads to an increased concentration of intracellular $\mathrm{Ca}^{2+}$. ${ }^{7}$ Increased calcium can trigger apoptosis, depolarization that activates lipases to break down neuron cell membranes, and mitochondrial dysfunction, leading to the generation of free radicals and reactive oxygen species (ROS). ${ }^{7}$

Several studies have investigated the relationship of venous and arterial blood gas parameters in critically ill human patients, ${ }^{8-13}$ and in rodent models ${ }^{14,15}$ demonstrating correlations between the blood gas values. Knowledge of blood gases could provide clinically valuable information about the cerebral infarct core and penumbra. To date, few studies have evaluated acid/base balance and electrolyte changes occurring within a few minutes of focal ischemia and occlusion. The aim of our study was to evaluate these changes, and to correlate them with infarct volume and/or mortality in two different rat models of stroke: permanent middle cerebral artery occlusion (MCAO) and transient MCAO. The permanent-MCAO model would mimic the natural history of large vessel 
occlusive stroke, while the transient-MCAO model accounts for recanalization seen in current treatment states that aim to re-establish flow.

\section{MATERIALS and METHODS}

\section{Permanent and Transient MCAO Model}

Three-month old Sprague-Dawley rats (ENVIGO, Indianapolis, IN) were used for all procedures. The rats weighed between 300 and 350 grams. The study was conducted in accordance with the National Institutes of Health (NIH) Guide for the Care and Use of Laboratory Animals and study protocols were approved through our Institutional Animal Care and Use Committee (IACUC). Animals were kept in a climate controlled room on a 12-hour light and dark cycle $(0700$ - 1900) with free access to food and water. For both models, animals were administered vehicle of phosphate buffered saline (PBS) at 7.4, at 6, 24, and 48 hours after MCAO.

For the permanent middle cerebral artery occlusion (pMCAO) procedure, as previously described, ${ }^{16}$ animals were placed in an induction chamber and anesthetized with 5\% isofluorane/oxygen. A constant flow of $3-4 \%$ isofluorane in $100 \%$ oxygen at a rate of 1 $\mathrm{L} / \mathrm{min}$ was maintained during the procedure. A vertical incision was made near the sternum to expose the right common carotid artery, and then a dissection was performed to isolate the common carotid and its branches. The first clamp was placed on the internal carotid prior to the pterygopalatine/internal cerebral artery (ICA) bifurcation, while the second clamp was placed on the common carotid artery. The placement of the second clamp further in the posterior direction allows more room for maneuvering during filament insertion. The external carotid was isolated, and used to access the arterial system. A 40mm nylon monofilament was fed distally into the intracranial artery to approximately $25 \mathrm{~mm}$, and then sutured in place to obtain permanent occlusion of the middle cerebral artery (MCA), M1 segment. The incision was closed with the filament in-place. A Laser Doppler (Moore Lab Instruments, Farmington, CT) monitored blood flow during the process. Animals that did not show $60 \%$ reduction in perfusion of blood flow after placement of the monofilament were excluded from the study. The transient MCAO (tMCAO) followed the same procedure, but the monofilament was removed and flow reestablished after 60 minutes. The transientMCAO rats $(n=19)$ were euthanized at 72 hours. The permanent-MCAO rats were euthanized at either $72(n=7)$ or 96 hours $(n=11)$. Brains from both models were harvested for infarct measurements.

Blood gas samples were collected and analyzed pre- and post-MCAO. An internal jugular line was inserted, prior to MCAO monofilament placement but after anesthesia induction, and an approximately $0.5 \mathrm{~mL}$ of venous blood sample was collected (representing the preMCAO sample). These venous systems of the brain drains into the sinus of confluence which splits to form the internal jugular veins, which is the final collecting port before returning to the heart. ${ }^{17}$ The majority of the venous blood samples were drawn on the ipsilateral side (affected MCAO side) of the animal. When the blood samples at the affected site were unable to be obtained, the blood draw occurred on the contralateral side (unaffected MCAO side). While the ipsilateral side location is preferred for consistency in our blood draw protocol, the blood is analogous due to the venous anatomy. It takes 
approximately 30 minutes to obtain the blood sample given the details of the MCAO procedure and anesthesia induction (represented by the shaded box for the variable time points, Figures $3 \mathrm{a}$ and 5a). The sample was analyzed using iSTAT Portable Clinical Analyzer (Abbott Laboratories, Abbott Park, IL). After pMCAO (approximately seven minutes), rats remained anesthetized on the operating table and venous blood sample was again collected (representing the post-MCAO sample) and analyzed with the iSTAT. pH, carbon dioxide $\left(\mathrm{pCO}_{2}\right)$, oxygen $\left(\mathrm{pO}_{2}\right)$, bicarbonate $\left(\mathrm{HCO}^{-}\right)$, base excess of extracellular fluid (beecf), glucose, and serum electrolytes, including ionized calcium $\left(\mathrm{iCa}^{2+}\right)$, potassium $\left(\mathrm{K}^{+}\right)$, and sodium $\left(\mathrm{Na}^{+}\right)$were analyzed. In the case of permanent MCAO, the post-MCAO sample was taken on average seven minutes after induction of the MCAO, while, in the case of the transient MCAO, the post-MCAO sample was taken approximately one hour and seven minutes after MCAO.

\section{Euthanasia and Tissue Preservation}

Animals were euthanized with Ketamine and Xylazine mixture $(75 \mathrm{mg} / \mathrm{kg}$ and $7.5 \mathrm{mg} / \mathrm{kg})$, at 72 or 96 hours after MCAO. They were perfused with $0.9 \%$ saline, then with $4 \%$ paraformaldehyde in PBS to remove blood from circulation and to preserve tissue. Brains were harvested in $4 \%$ paraformaldehyde, and then shifted to 20 to $30 \%$ sucrose for cryopreservation. Six coronal brain sections were cut $(30 \mu \mathrm{m})$ with a cryostat and taken from +1.7 to $-3.3 \mathrm{~mm}$ bregma coordinates. Coronal sections were mounted on glass slides and stored at $-20^{\circ} \mathrm{C}$. To label degenerating neurons Fluoro-Jade staining (Histochem, Jefferson, AR) was used. This method has been previously detailed. ${ }^{18}$ To rehydrate the coronal sections, $100 \%$ ethanol was used for three minutes, followed by a minute each in $70 \%$ ethanol and deionized water. Sections were then Fluoro-Jade stained $(0.001 \%$ solution in $0.1 \%$ acetic acid) for 30 minutes. Slides were rinsed and dried at $45^{\circ} \mathrm{C}$ for 20 minutes, and then coverslipped with DPX mounting medium (Electron Microscopy Sciences, Ft. Washington, PA).

\section{Infarct Volume Analysis}

Coronal brain sections (bregma coordinates +1.7 through $-3.3 \mathrm{~mm}$ ) were collected from rats in both models. A Zeiss AxioSkop2 microscope (model 801572) with a Zeiss AxioCam Color camera (model 412-312, Oberkochen, Germany) was used with OpenLab imaging software (Improvision Ltd., Lexington, MA) to capture images. Total infarct volumes were measured with NIH Image $\mathbf{J}$ software by taking the damaged ipsilateral hemisphere and dividing the total area of the contralateral hemisphere (six sections of each brain) measurement and multiplying by 100 to obtain a percentage. Infarct volume measurement equation: ipsilateral/contralateral $\times 100=$ percentage .

\section{Statistical Analyses and Sample Size}

Before conducting statistical analyses, variables were transformed to meet assumptions of normality. Data from both MCAO models were analyzed using SPSS, version 24 software (SPSS, Inc., Chicago, IL). Data analysis began with a descriptive examination of all variables, including frequency distribution, means, and standard deviations. Paired samples t-tests were used to compare venous blood gas differences in mean scores between pre- and post-MCAO samples. Multiple linear regression with backward variable entry was 
performed in the permanent and transient models to determine the correlations of venous blood gas and electrolyte changes to infarct volume. The variables were entered into the model at once. The adjusted $\mathrm{R}^{2}$ was used to determine the variance explained in infarct volume. The P-to-P plot was used to assess the changes in $\mathrm{pH}$ and $\mathrm{iCa}^{2+}$ data sets for normal distribution. Multicollinearity was assessed by examining correlation coefficients and tolerance/variance inflation factor values. A Kaplan-Meier curve using Mantel-Haenszel logrank test analysis was performed to analyze mortality between permanent and transientMCAO models. A p-value of 0.05 was set a priori to determine statistical significance.

The total sample size for the permanent MCAO model was 18 . These animals are furthered categorized into those that survived to 72 hours $(n=11)$, and those that died prior to 72 hours $(n=7)$. In comparison, the total sample size for transient MCAO was 19. These animals are also divided into those that survived to 72 hours $(n=17)$, and those that died before 72 hours $(n=2)$. Total sample size for both models was reduced during the iSTAT blood sample collection due to individual readings errors. Errors were excluded from statistical tests.

\section{RESULTS}

\section{Relationship Between MCAO Model and Mortality}

A Kaplan-Meier curve and Mantel-Haenszel log-rank test was used to analyze event-free survival between permanent and transient MCAO models $(\mathrm{p}=0.045)$. Approximately $39 \%$ mortality was seen in the permanent model, while an average of $11 \%$ occurred in the transient model. The mortality rates were collected at four different time points; 6 hours, 24 hours, 48 hours, and 72 hours. In the permanent model $(n=18)$, seven rats died at 24 hours and 11 rats survived up to 72 hours. By comparison, the transient model $(n=19)$ rats exhibited greater survival, with one death at 6 hours and one other at 24 hours; the remaining animals $(\mathrm{n}=17)$ survived up to 72 hours (Figure 1$)$. The permanent-MCAO infarct volumes ranged from 24.40 to $90.79 \%$ (Figure 2a). The transient-MCAO infarct volumes ranged from 12.07 to $33.34 \%$ (Figure $2 \mathrm{~b}$ ). There is no significant difference in infarct size between transient and permanent occlusion.

\section{Permanent MCAO Model}

In the permanent MCAO model, there were several significant differences in the blood gas analysis between pre- and post-MCAO (Figure $3 \mathrm{~b}$ ). These included significant decrease in $\mathrm{pH}(\mathrm{p}=0.035)$, Beecf $(\mathrm{p}=0.001)$, and $\mathrm{Na}^{+}(\mathrm{p}<0.001)$, as wells as increases in $\mathrm{pCO}_{2}(\mathrm{p}=$ $0.036), \mathrm{K}^{+}(\mathrm{p}=0.006), \mathrm{iCa}^{2+}(\mathrm{p}=0.045)$, and glucose $(\mathrm{p}<0.001)$. Multiple regression analysis in the permanent-MCAO model $(\mathrm{n}=11)$ showed that the changes in $\mathrm{pH}$ and in $\mathrm{iCa}^{2+}$ were significantly correlated to infarct volume $(\mathrm{F}(2,8)=16.582, \mathrm{p}=0.001)$. This indicates a negative correlation between $\mathrm{pH}$ and ionized calcium together with the extent of the infarct, as changes in $\mathrm{pH}$ and calcium decreased, infarct volume increased. These variables explained $76 \%$ of the total variance in the model, as predictors of infarct volume (Figure 4a and 4b). 


\section{Transient MCAO Model}

In the transient MCAO model, there were also several significant differences in blood gas analysis between pre- and post- MCAO (Figure $5 b)$. These included decreases in $\mathrm{pH}(\mathrm{p}=$ $0.004)$ and $\mathrm{Na}^{+}(\mathrm{p}=0.002)$, as well as increases in $\mathrm{pCO}_{2}(\mathrm{p}=0.024) ; \mathrm{K}^{+}(\mathrm{p}<0.001), \mathrm{iCa}^{2+}$ $(p=0.015)$, glucose $(p=0.047)$, hematocrit $(p<0.001)$, and hemoglobin $(p<0.001)$. Unlike the permanent model, Beecf $(p=0.397)$ was not significantly altered. None of the acid/base changes or electrolyte changes in the transient-MCAO model correlated to infarct volume.

\section{DISCUSSION}

To our knowledge our study demonstrates, for the first time, rapid changes in venous blood gases and electrolytes occurring immediately following cerebral ischemia in two separate MCAO rat models (permanent and transient). Furthermore, we establish a statistically significant correlation between some of those changes and infarct volume. Significant differences were seen between the two models for mortality. Our blood analyses follow the biochemical changes reported in other cerebral occlusion studies in animals and humans. We report that significant systemic changes in blood chemistry occurs very rapidly after occlusion with an average of seven minutes in the permanent MCAO model, and approximately one hour and seven minutes in the transient MCAO model. To our knowledge, we have not found any other studies that examined these changes so early after occlusion and in two separate MCAO models.

We used the permanent and transient MCAO models for two separate reasons. First, we aimed to identify ultra-early changes in a permanent model of ischemia. While there are a host of signaling cascades that occur in multiple pathways to induce injury, apoptosis, and necrosis after stroke, we evaluated the relationship between these ultra-early changes and eventual outcome. Second, and separately, we wanted to plot the course of blood gas and electrolyte changes upon early reperfusion. As recanalization strategies such as tissue plasminogen activator (tPA) and mechanical thrombectomy have become standard of care, it is important to understand pathologic changes in stroke in the context of acute recanalization. The permanent model is an evaluation of large vessel occlusive stroke in its natural history. ${ }^{19}$ The majority of patients who experience an ischemic stroke do not receive tPA and/or mechanical thrombectomy. ${ }^{20,21}$ The transient model is an evaluation of the effect of treatment, because it mimics the human condition for receiving tPA and/or mechanical thrombectomy and the reperfusion event. The transient model evaluates the persistency of changes in acid/base and electrolytes immediately after reperfusion.

This study combined all blood measurements to determine association with infarct volume. In evaluating the early changes in acid/base and electrolytes in the permanent model the multiple linear regression showed significance in changes of $\mathrm{pH}$ and $\mathrm{iCa}^{2+}$ to infarct volume in the permanent model. These two variables clearly have an interrelationship to infarct volume, but causality needs to be furthered evaluated in future studies.

In human stroke patients, lower venous total serum calcium concentrations were associated with more severe clinical symptoms following stroke onset, worse functional outcomes, and hemorrhagic transformation post-thrombectomy. ${ }^{22-24}$ Conversely, higher venous total serum 
calcium levels detected on admission or within 24 hours of stroke onset in acute ischemic stroke patients were associated with better functional outcomes and reduced cerebral infarcts. ${ }^{25-27}$ These findings reflect increased serum calcium levels are linked to positive stroke outcomes. Our study indicates an inverse relationship with changes in ionized calcium and infarct volume; however, this is based on immediate ionized calcium $\left(\mathrm{iCa}^{2+}\right)$ changes, not total calcium serum. Furthermore, our measurements were within minutes to hours of the infarct induction, while the previous studies above included levels drawn within 24 hours of admission. Therefore, there may be a calcium concentration curve that is temporal in nature as it relates to infarct. Further temporal studies are needed to map this relationship.

While we found no correlations with changes in $\mathrm{Na}^{+}$with infarct volumes, several reports with contradictory results show serum $\mathrm{Na}^{+}$levels are associated with stroke severity in human patients. Rodrigues et al. ${ }^{28}$ and Soiza et al. ${ }^{29}$ found patients with lower sodium or hyponatremia were associated with stroke severity and mortality. Other studies have observed higher venous serum sodium concentrations were associated with stroke incidence and neurological worsening. ${ }^{30-32}$ Serum $\mathrm{Na}^{+}$levels in the control group was lower than in patients with transient ischemic attack, and with ischemic and hemorrhagic strokes. ${ }^{33}$ Our findings are similar in showing changes in serum $\mathrm{Na}^{+}$levels from pre-to post- pMCAO, but the significance of these changes needs to be elucidated. Again, the timing of sampling may have an effect on the power of the association. It may be the case that our early-timed assay does not reflect changes that occur in the first 24 to 48 hours.

The transient MCAO model did not show correlations in the multiple linear regression model. We believe this is due to the magnitude of the changes of acid/base and electrolytes may be masked by the benefit of reperfusion. While we saw many similar differences in changes from pre- to post-MCAO (compared to the permanent model), the animals did not have an infarct volume variance that correlated. This may reflect the overpowering effect of recanalization and reperfusion on dictating final infarct volume. Further studies will need to be conducted to address these issues.

Another interesting difference between the two models was noting the significant differences of increased hematocrit and hemoglobin pre- to post-MCAO in the transient model, most likely due to hemoconcentration of fluid losses (urination, temperature or insensible losses), which is often seen in human ischemic stroke patients. This was not observed in the permanent model perhaps due to the timing of the second iSTAT collection, where animals may not have had an opportunity to compensate yet; these are issues that need to be addressed in future studies.

The transient model had better survival rate than the permanent model and the difference between the groups is statistically significant $(\mathrm{p}=0.045)$. The permanent model shows animal deaths occurred at various time points post-MCAO with the majority occurring at 24 hours. The 24-hour time point is critical in human ischemic stroke patients because this is the period when patients experience edema, herniation, and hemorrhagic conversion resulting in increased mortality. ${ }^{34} \mathrm{We}$ did not find this in the transient model, which verifies the importance of reperfusion in ischemic stroke and survival outcomes. 
In this study, we demonstrated early significant changes of blood gases and electrolyte concentrations after induction of a middle cerebral artery occlusion stroke. This study shows that blood chemistry in the systemic circulation responds rapidly to the ischemic event in the brain. Other studies examined one stroke model and one blood gas parameter or electrolyte concentration, while we analyzed two separate MCAO models in rats and the whole blood gas and electrolyte panel. Previous studies have shown variability in their results, however, our study shows the initial changes in $\mathrm{pH}$ and ionized calcium are predictors of infarct volume in the permanent MCAO model. Our future studies will examine aged male and female rats to address whether age and sex affects this issue. Eventually we are planning to expand our blood gas studies to humans to determine if these results translate to human stroke patients, which would allow early prediction of the stroke outcome.

\title{
Acknowledgments
}

\author{
N/A \\ Funding Statement:
}

This work was supported by National Institutes of Health, National Institute of Neurological Disorders and Stroke (NINDS), grant number NS091146.

\section{References}

1. Go AS, Mozaffarian D, Roger VL, et al. Executive summary: heart disease and stroke statistics2014 update: a report from the american heart association. Circulation. 2014; 129:399-410 12. [PubMed: 24446411]

2. Borgens RB, Liu-Snyder P. Understanding secondary injury. Q Rev Biol. 2012; 87:89-127. [PubMed: 22696939]

3. Kristian T, Siesjo BK. Changes in ionic fluxes during cerebral ischaemia. Int Rev Neurobiol. 1997; 40:27-45. [PubMed: 8989615]

4. Casey JR, Grinstein S, Orlowski J. Sensors and regulators of intracellular pH. Nat Rev Mol Cell Biol. 2010; 11:50-61. [PubMed: 19997129]

5. Back T, Hoehn M, Mies G, et al. Penumbral tissue alkalosis in focal cerebral ischemia: relationship to energy metabolism, blood flow, and steady potential. Ann Neurol. 2000; 47:485-92. [PubMed: 10762160]

6. Traystman RJ, Kirsch JR, Koehler RC. Oxygen radical mechanisms of brain injury following ischemia and reperfusion. Journal of applied physiology (Bethesda, Md : 1985). 1991; 71:1185-95.

7. Mifsud G, Zammit C, Muscat R, Di Giovanni G, Valentino M. Oligodendrocyte pathophysiology and treatment strategies in cerebral ischemia. CNS Neurosci Ther. 2014; 20:603-12. [PubMed: 24703424]

8. Ak A, Ogun CO, Bayir A, Kayis SA, Koylu R. Prediction of arterial blood gas values from venous blood gas values in patients with acute exacerbation of chronic obstructive pulmonary disease. Tohoku J Exp Med. 2006; 210:285-90. [PubMed: 17146193]

9. Awasthi S, Rani R, Malviya D. Peripheral venous blood gas analysis: An alternative to arterial blood gas analysis for initial assessment and resuscitation in emergency and intensive care unit patients. Anesthesia, essays and researches. 2013; 7:355-8.

10. Esmaeilivand M, Khatony A, Moradi G, Najafi F, Abdi A. Agreement and Correlation between Arterial and Central Venous Blood Gas Following Coronary Artery Bypass Graft Surgery. Journal of clinical and diagnostic research : JCDR. 2017; 11:Oc43-oc6. [PubMed: 28511435]

11. Kelly AM, McAlpine R, Kyle E. Venous $\mathrm{pH}$ can safely replace arterial $\mathrm{pH}$ in the initial evaluation of patients in the emergency department. Emerg Med J. 2001; 18:340-2. [PubMed: 11559602] 
12. Khan ZH, Samadi S, Sadeghi M, et al. Prospective study to determine possible correlation between arterial and venous blood gas values. Acta anaesthesiologica Taiwanica : official journal of the Taiwan Society of Anesthesiologists. 2010; 48:136-9. [PubMed: 20864062]

13. Treger R, Pirouz S, Kamangar N, Corry D. Agreement between central venous and arterial blood gas measurements in the intensive care unit. Clin J Am Soc Nephrol. 2010; 5:390-4. [PubMed: 20019117]

14. Schwarzkopf TM, Horn T, Lang D, Klein J. Blood gases and energy metabolites in mouse blood before and after cerebral ischemia: the effects of anesthetics. Exp Biol Med (Maywood). 2013; 238:84-9. [PubMed: 23479767]

15. Son KH, Lim CH, Song EJ, Sun K, Son HS, Lee SH. Inter-species hemorheologic differences in arterial and venous blood. Clin Hemorheol Microcirc. 2010; 44:27-33. [PubMed: 20134090]

16. Ajmo CT Jr, Vernon DO, Collier L, et al. The spleen contributes to stroke-induced neurodegeneration. J Neurosci Res. 2008; 86:2227-34. [PubMed: 18381759]

17. Meder JF, Chiras J, Roland J, Guinet P, Bracard S, Bargy F. Venous territories of the brain. J Neuroradiol. 1994; 21:118-33. [PubMed: 8014657]

18. Duckworth EA, Butler TL, De Mesquita D, Collier SN, Collier L, Pennypacker KR. Temporary focal ischemia in the mouse: technical aspects and patterns of Fluoro-Jade evident neurodegeneration. Brain Res. 2005; 1042:29-36. [PubMed: 15823250]

19. McBride DW, Zhang JH. Precision Stroke Animal Models: the Permanent MCAO Model Should Be the Primary Model, Not Transient MCAO. Translational stroke research. 2017

20. Messe SR, Khatri P, Reeves MJ, et al. Why are acute ischemic stroke patients not receiving IV tPA? Results from a national registry. Neurology. 2016; 87:1565-74. [PubMed: 27629092]

21. Bhole R, Goyal N, Nearing K, et al. Implications of limiting mechanical thrombectomy to patients with emergent large vessel occlusion meeting top tier evidence criteria. J Neurointerv Surg. 2017; 9:225-8. [PubMed: 26932801]

22. Guven H, Cilliler AE, Koker C, Sarikaya SA, Comoglu SS. Association of serum calcium levels with clinical severity of acute ischemic stroke. Acta Neurol Belg. 2011; 111:45-9. [PubMed: 21510233]

23. Ishfaq M, Ullah F, Akbar S, Rahim F, Afridi AK. Correlation of serum calcium with severity of acute ischaemic stroke. J Pak Med Assoc. 2017; 67:20-3. [PubMed: 28065948]

24. Guo Y, Yan S, Zhang S, et al. Lower serum calcium level is associated with hemorrhagic transformation after thrombolysis. Stroke. 2015; 46:1359-61. [PubMed: 25813194]

25. Buck BH, Liebeskind DS, Saver JL, et al. Association of higher serum calcium levels with smaller infarct volumes in acute ischemic stroke. Arch Neurol. 2007; 64:1287-91. [PubMed: 17846267]

26. Ovbiagele B, Liebeskind DS, Starkman S, et al. Are elevated admission calcium levels associated with better outcomes after ischemic stroke? Neurology. 2006; 67:170-3. [PubMed: 16832104]

27. Ovbiagele B, Starkman S, Teal P, et al. Serum calcium as prognosticator in ischemic stroke. Stroke. 2008; 39:2231-6. [PubMed: 18583560]

28. Rodrigues B, Staff I, Fortunato G, McCullough LD. Hyponatremia in the prognosis of acute ischemic stroke. J Stroke Cerebrovasc Dis. 2014; 23:850-4. [PubMed: 23954607]

29. Soiza RL, Cumming K, Clark AB, et al. Hyponatremia predicts mortality after stroke. Int J Stroke. 2015; 10(Suppl A100):50-5. [PubMed: 26178714]

30. Fofi L, Dall'armi V, Durastanti L, et al. An observational study on electrolyte disorders in the acute phase of ischemic stroke and their prognostic value. J Clin Neurosci. 2012; 19:513-6. [PubMed: 22321365]

31. Farahmand F, Choobi Anzali B, Heshmat R, Ghafouri HB, Hamedanchi S. Serum Sodium and Potassium Levels in Cerebro-vascular Accident Patients. Malays J Med Sci. 2013; 20:39-43.

32. Christensen H, Boysen G. Blood glucose increases early after stroke onset: a study on serial measurements of blood glucose in acute stroke. Eur J Neurol. 2002; 9:297-301. [PubMed: 11985639]

33. Grotta J, Ackerman R, Correia J, Fallick G, Chang J. Whole blood viscosity parameters and cerebral blood flow. Stroke. 1982; 13:296-301. [PubMed: 7080121] 
34. Dostovic Z, Dostovic E, Smajlovic D, Ibrahimagic OC, Avdic L. Brain Edema After Ischaemic Stroke. Medical archives (Sarajevo, Bosnia and Herzegovina). 2016; 70:339-41. 


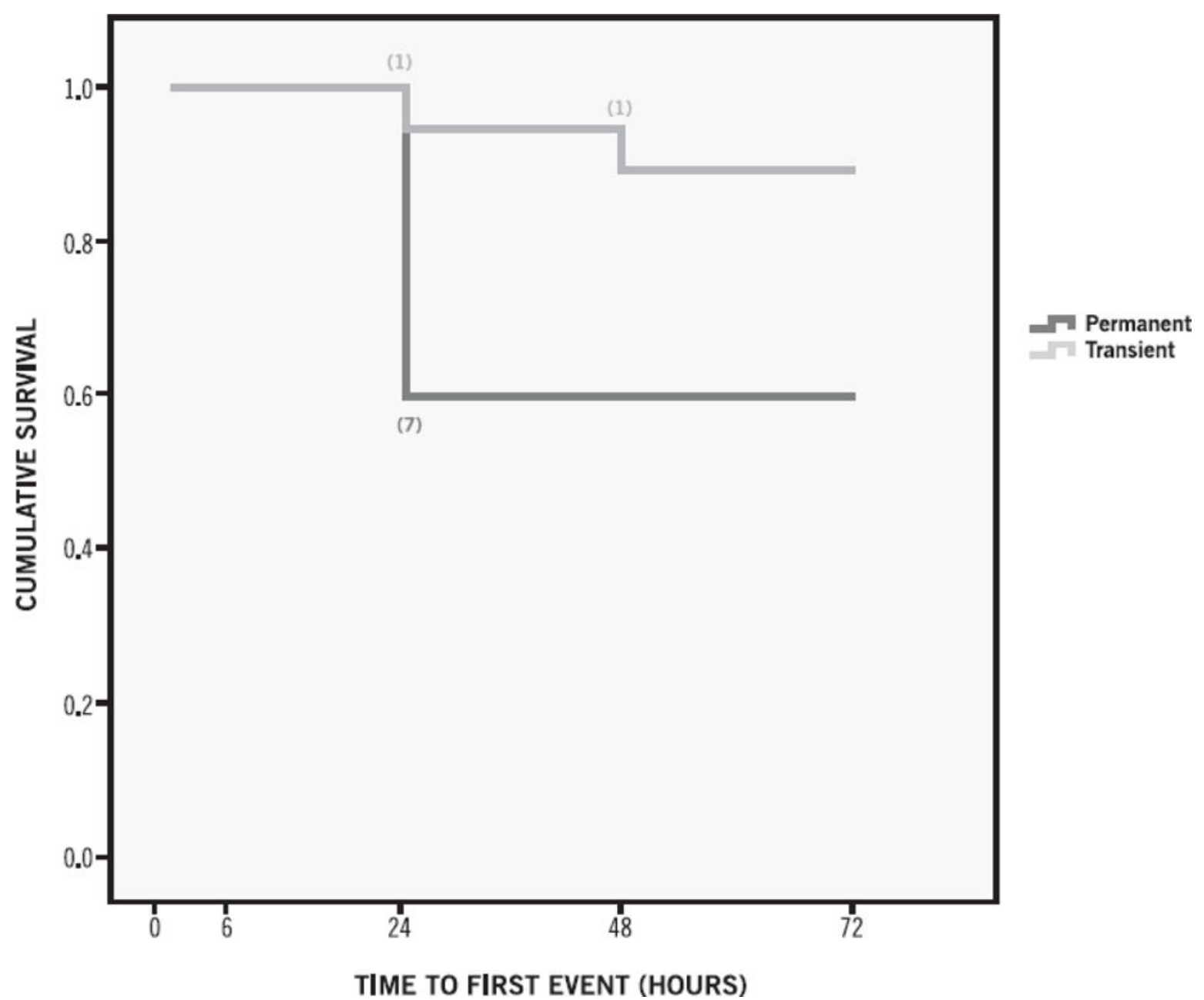

Figure 1.

Mortality data expressed using the Kaplan-Meier curve and analysis using the MantelHaenszel log-rank test revealed significant difference in survival between permanent and transients $(\mathrm{p}=0.045)$. The numbers in parentheses represent the mortality of rats at 24 hours and 48 hours. The surviving rats in the permanent model were $n=11$. The surviving rats in the transient model were $n=17$. 


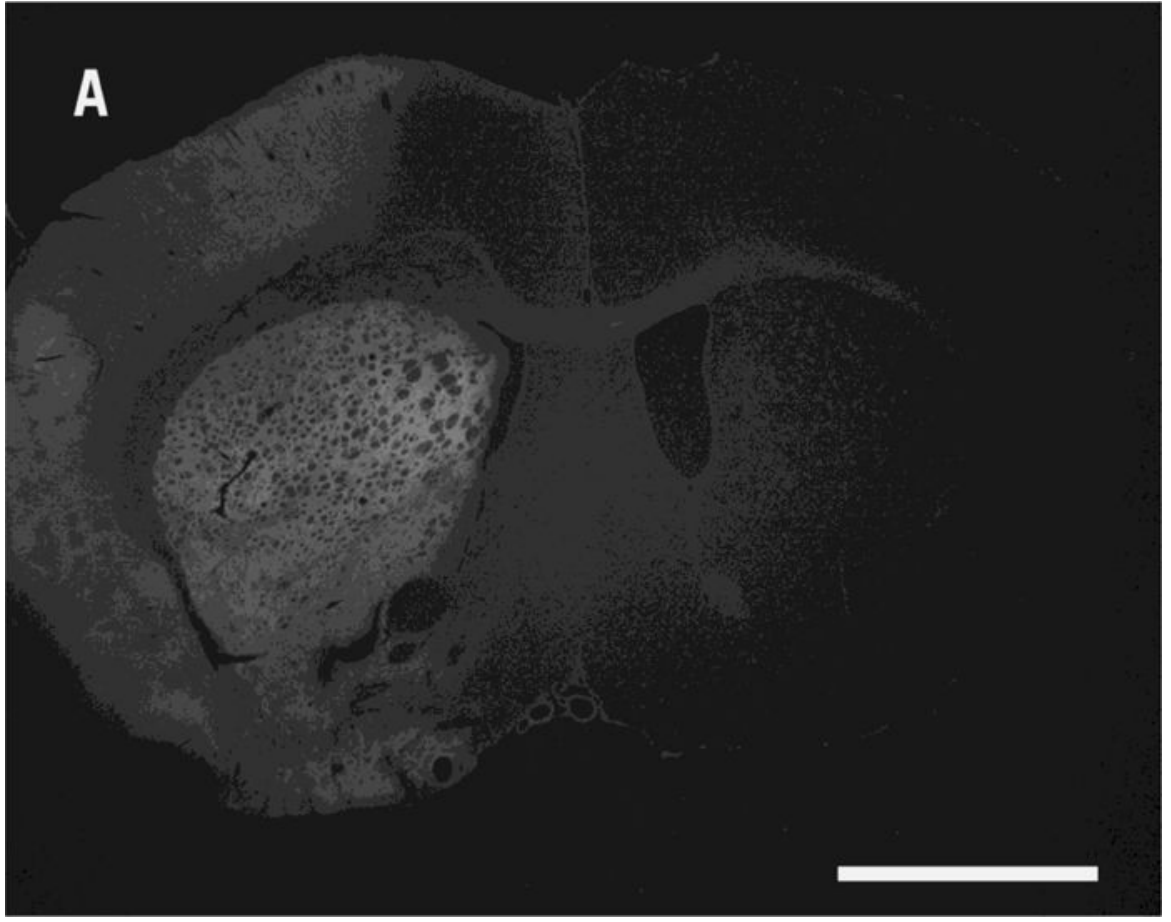

Figure 2a.

Representative permanent-MCAO infarct volume image. Fluoro-Jade staining was performed on cryosections from rat brains to identify the damaged neurons 72 hours postMCAO. The range for permanent-MCAO infarct volumes were $24.40-90.79 \%$. Scale bars $=150 \mu \mathrm{m}$. 


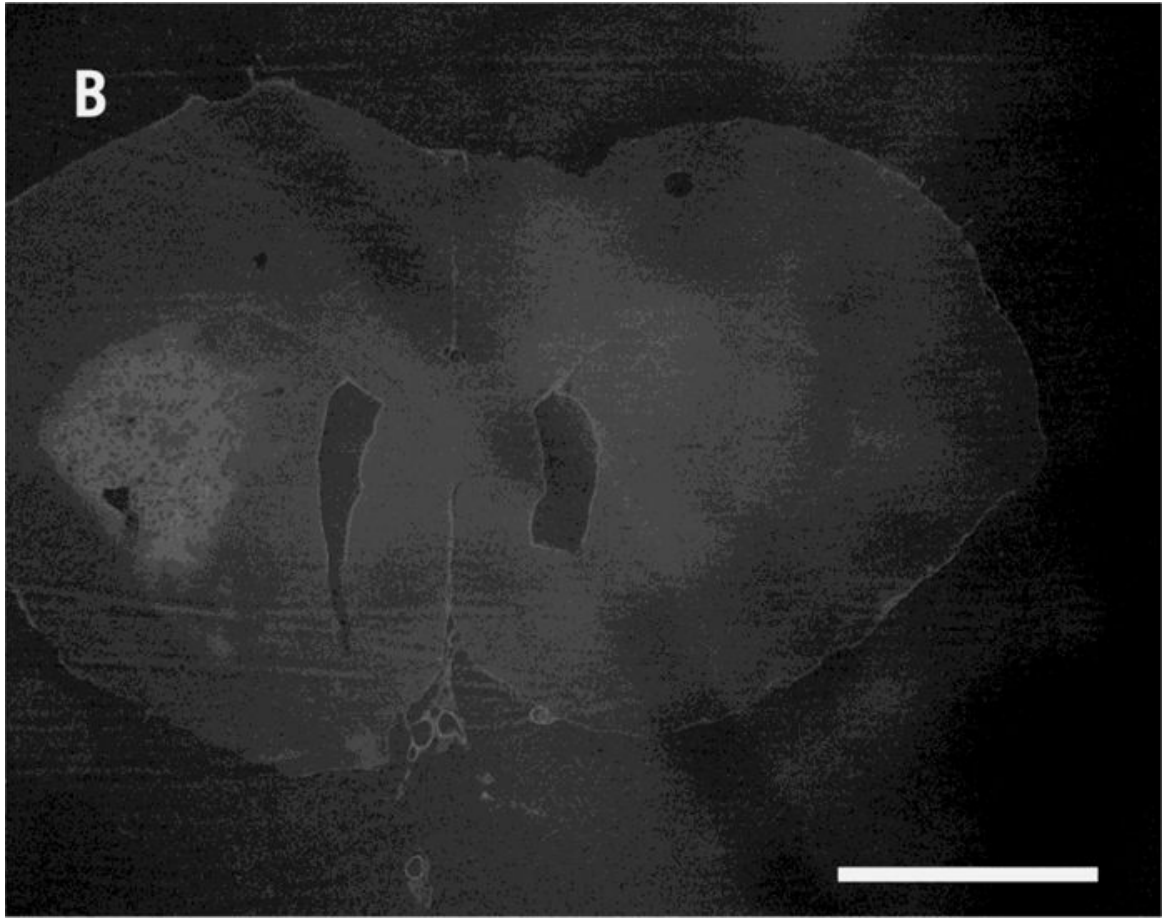

Figure 2b.

Representative transient-MCAO infarct volume image. Fluoro-Jade staining was performed on cryosections from rat brains to identify the damaged neurons 72 hours post-MCAO. The transient-MCAO infarct volumes ranged from $12.07-33.34 \%$. Scale bars $=150 \mu \mathrm{m}$. 


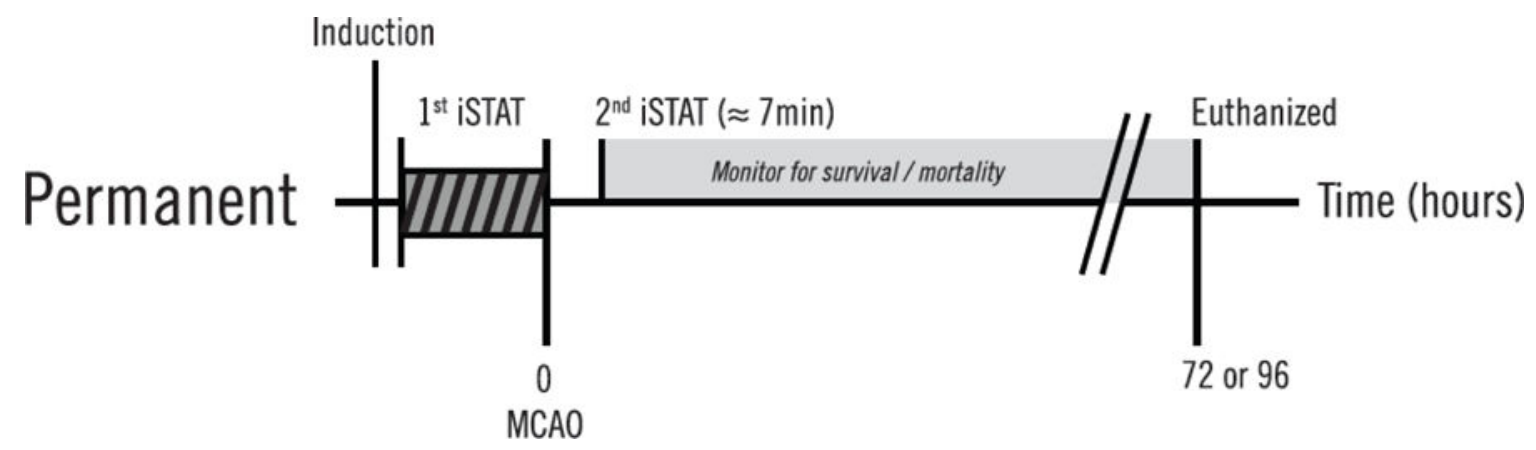

Figure 3a. Permanent Timeline

The time point from the first venous blood sample (represented by $1^{\text {st }}$ iSTAT) to MCAO is a variable time period due to anesthesia induction and MCAO procedure, taking roughly 30 minutes to obtain the sample (represented by the shaded box). In the pMCAO, the postMCAO sample was taken approximately seven minutes after induction of the MCAO (represented by $2^{\text {nd }}$ iSTAT). 


\begin{tabular}{|c|c|c|c|c|c|}
\hline & \multicolumn{5}{|c|}{ Permanent MCAO } \\
\hline Parameters & $\mathrm{n}$ & $\begin{array}{l}\text { Pre-MCAO } \\
\text { Mean } \pm \text { SD }\end{array}$ & $\begin{array}{l}\text { Post-MCAO } \\
\text { Mean } \pm \text { SD }\end{array}$ & $\begin{array}{c}\Delta \\
\text { Mean } \pm \text { SD }\end{array}$ & p-Value \\
\hline $\mathrm{pH}$ & 14 & $7.249 \pm 0.071$ & $7.217 \pm 0.075$ & $0.033 \pm 0.052$ & 0.035 \\
\hline $\mathrm{pCO}_{2}$ (mmHg) & 14 & $69.660 \pm 9.397$ & $75.890 \pm 14.190$ & $-6.229 \pm 9.944$ & 0.036 \\
\hline $\mathrm{pO}_{2}(\mathrm{mmHg})$ & 14 & $105.929 \pm 18.269$ & $107.357 \pm 21.685$ & $-1.429 \pm 18.711$ & 0.780 \\
\hline BEecf (mmol/L) & 14 & $4.36 \pm 1.008$ & $3.070 \pm 1.328$ & $1.286 \pm 1.069$ & 0.001 \\
\hline $\mathrm{HCO}^{3-}(\mathrm{mmol} / \mathrm{L})$ & 14 & $31.380 \pm 1.196$ & $31.550 \pm 2.008$ & $-0.171 \pm 1.082$ & 0.564 \\
\hline $\mathrm{Na}^{+}(\mathrm{mmol} / \mathrm{L})$ & 14 & $133.570 \pm 1.222$ & $131.930 \pm 1.439$ & $1.643 \pm 1.216$ & $<0.001$ \\
\hline $\mathrm{K}^{+}(\mathrm{mmol} / \mathrm{L})$ & 14 & $4.450 \pm 0.231$ & $4.711 \pm 0.408$ & $-0.261 \pm 0.296$ & 0.006 \\
\hline $\mathrm{iCa}^{2+}(\mathrm{mmol} / \mathrm{L})$ & 14 & $1.091 \pm 0.138$ & $1.190 \pm 0.087$ & $-0.099 \pm 0.168$ & 0.045 \\
\hline Glu (mg/dL) & 14 & $290.290 \pm 31.067$ & $368.790 \pm 58.380$ & $-78.500 \pm 47.383$ & $<0.001$ \\
\hline Hct (\% PCV) & 14 & $40.214 \pm 1.424$ & $40.429 \pm 1.651$ & $-0.214 \pm 0.893$ & 0.385 \\
\hline $\mathrm{Hbg}(\mathrm{g} / \mathrm{dL})$ & 14 & $13.679 \pm 0.474$ & $13.743 \pm 0.543$ & $-0.064 \pm 0.295$ & 0.430 \\
\hline
\end{tabular}

Data are presented as mean \pm standard deviations. $\mathrm{pCO}_{2}$ : Partial pressure of carbon dioxide $(\mathrm{mmHg}) ; \mathrm{pO}_{2}$ : partial pressure of oxygen $(\mathrm{mmHg}) ; B E e c f$ : base excess of extracellular fluid (mmol/L); $\mathrm{HCO}^{5}$ bicarbonate (mmol/L); s $\mathrm{O}^{2}$ : oxygen saturation (\%); $\mathrm{Na+:}$ sodium (mmol/L);

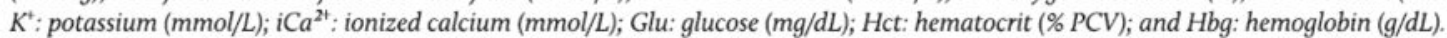

Figure 3b. Permanent Model

Venous blood paired samples T-Test in pre- and post- MCAO Sprague Dawley rats. 


\begin{tabular}{|l|l|l|l|l|}
\hline Variable & B & SE B & $\beta$ & p value \\
\hline$\Delta \mathrm{pH}$ & -86.155 & 21.050 & -0.640 & 0.003 \\
\hline$\Delta \mathrm{iCa}^{2+}$ & -99.878 & 22.994 & -0.679 & 0.002 \\
\hline
\end{tabular}

$R^{2}=0.806$, adjusted $R^{2}=0.757, d f=2, F=16.582$, Durbin-Watson $=1.730$

Figure 4. Permanent Model

Multiple regression was performed to determine the correlations of venous blood gas and electrolyte changes to infarct volume. As changes in $\mathrm{pH}$ and ionized calcium decrease, infarct volume increases. These variables explained $\approx 76 \%$ of the total variance in the model as predictors of infarct volume in the permanent model.

Figure 4a: Multiple linear regression variables predicting infarct volume in permanentMCAO rats $(n=11)$. 


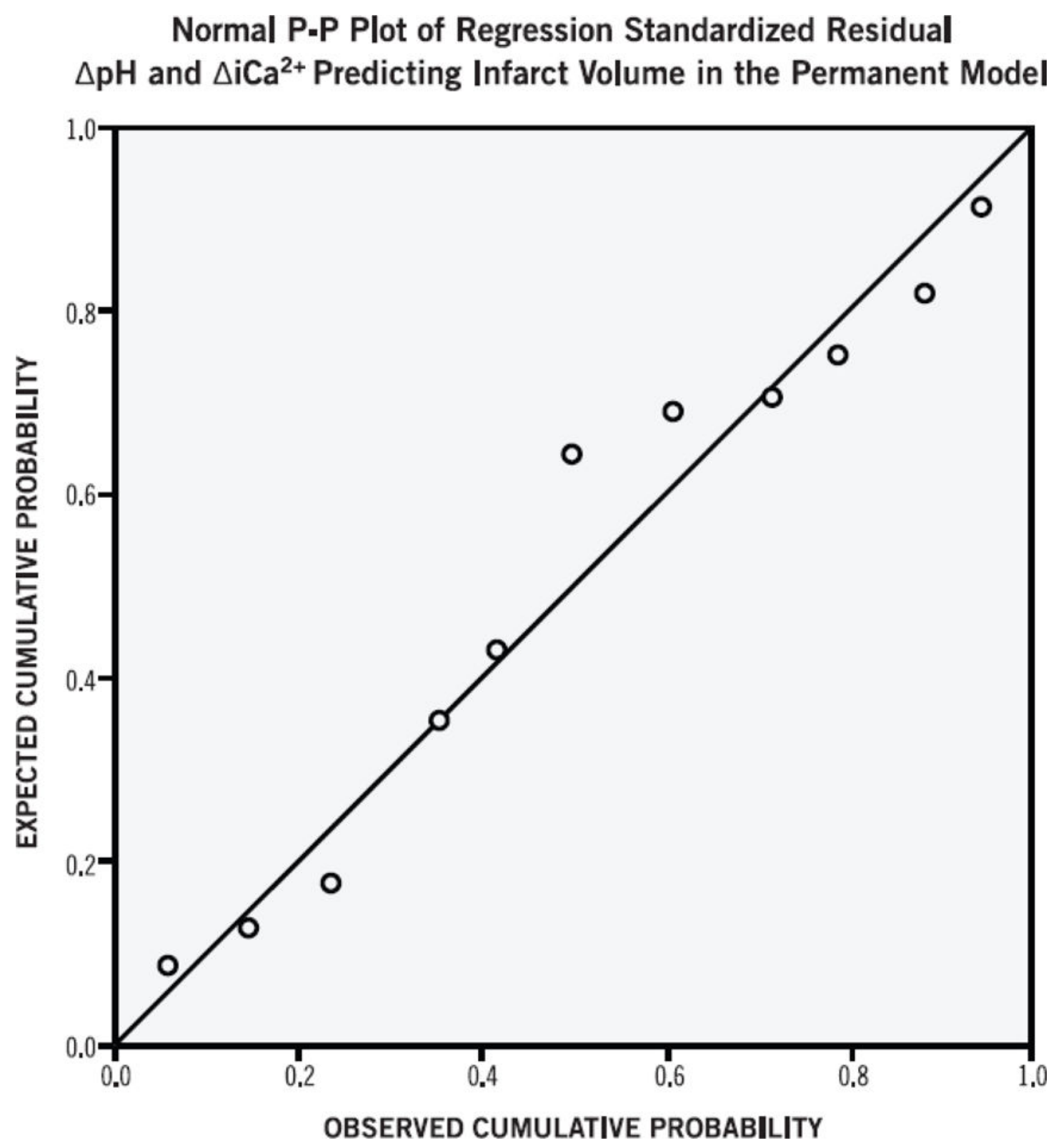

Figure 4b. Permanent Model

$\mathrm{P}-\mathrm{P}$ plot of residuals for change in $\mathrm{pH}$ and $\mathrm{iCa}^{2+}$ predicting infarct volume. 


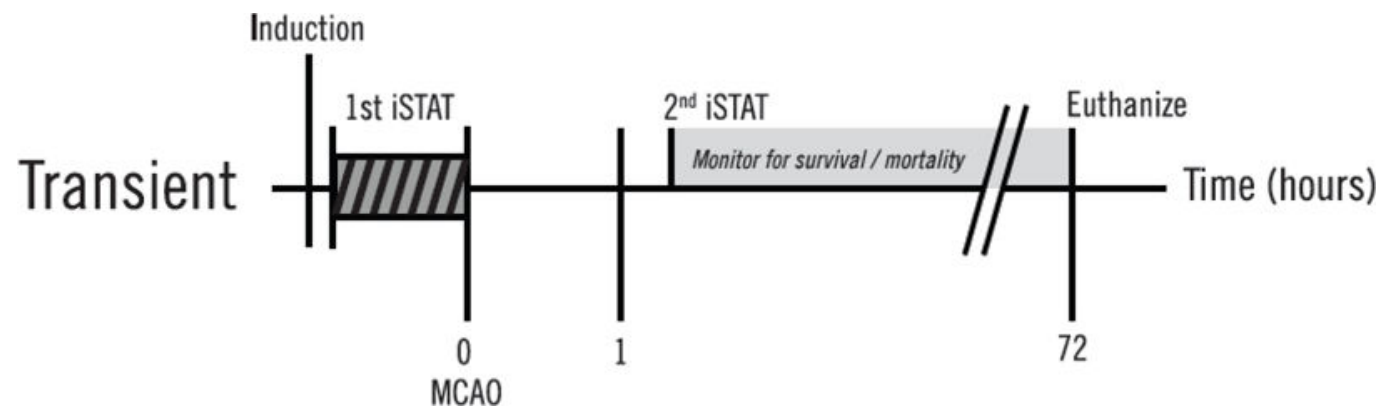

Figure 5a. Transient Timeline

The time point from the first venous blood sample (represented by $1^{\text {st }}$ iSTAT) to MCAO is a variable time period due to anesthesia induction and MCAO procedure, taking approximately 30 to obtain blood sample (represented by the shaded box). In the tMCAO, the post-MCAO sample was taken on average one hour and seven minutes after MCAO (represented by $2^{\text {nd }}$ iSTAT). 


\begin{tabular}{|c|c|c|c|c|c|}
\hline \multirow[b]{2}{*}{ Parameters } & \multicolumn{5}{|c|}{ Transient MCAO } \\
\hline & $n$ & $\begin{array}{l}\text { Pre-MCAO } \\
\text { Mean } \pm \text { SD }\end{array}$ & $\begin{array}{l}\text { Post-MCA0 } \\
\text { Mean } \pm \text { SD }\end{array}$ & $\begin{array}{c}\Delta \\
\operatorname{Mean} \pm \text { SD }\end{array}$ & p-Value \\
\hline $\mathrm{pH}$ & 12 & $7.263 \pm 0.060$ & $7.106 \pm 0.143$ & $0.157 \pm 0.152$ & 0.004 \\
\hline $\mathrm{pCO}_{2}$ (mmHg) & 9 & $71.490 \pm 14.155$ & $93.530 \pm 26.149$ & $-22.044 \pm 23.760$ & 0.024 \\
\hline $\mathrm{pO}_{2}$ (mmHg) & 12 & $139.000 \pm 26.823$ & $149.833 \pm 42.734$ & $-10.833 \pm 41.772$ & 0.388 \\
\hline BEecf (mmol/L) & 9 & $4.440 \pm 1.810$ & $4.110 \pm 1.537$ & $0.333 \pm 1.118$ & 0.397 \\
\hline $\mathrm{HCO}^{3-}(\mathrm{mmol} / \mathrm{L})$ & 9 & $31.310 \pm 1.745$ & $32.270 \pm 2.502$ & $-0.956 \pm 1.731$ & 0.136 \\
\hline $\mathrm{Na}^{+}(\mathrm{mmol} / \mathrm{L})$ & 12 & $133.83 \pm 1.030$ & $131.83 \pm 1.749$ & $2.000 \pm 1.758$ & 0.002 \\
\hline $\mathrm{K}^{+}(\mathrm{mmol} / \mathrm{L})$ & 12 & $4.342 \pm 0.144$ & $4.933 \pm 0.485$ & $-0.592 \pm 0.414$ & $<0.001$ \\
\hline $\mathrm{iCa}^{2+}(\mathrm{mmol} / \mathrm{L})$ & 12 & $1.104 \pm 0.151$ & $1.222 \pm 0.114$ & $-0.118 \pm 0.141$ & 0.015 \\
\hline Glu (mg/dL) & 12 & $305.330 \pm 27.003$ & $372.080 \pm 114.099$ & $-66.750 \pm 103.660$ & 0.047 \\
\hline Hct (\% PCV) & 12 & $39.000 \pm 1.595$ & $41.750 \pm 2.137$ & $-2.750 \pm 1.138$ & $<0.001$ \\
\hline $\mathrm{Hbg}(\mathrm{g} / \mathrm{dL})$ & 12 & $13.250 \pm 0.525$ & $14.200 \pm 0.727$ & $-0.950 \pm 0.397$ & $<0.001$ \\
\hline
\end{tabular}

Data are presented as mean \pm standard deviations. $\mathrm{pCO}_{2}$ : Partial pressure of carbon dioxide $(\mathrm{mmHg}) ; \mathrm{pO}_{2}$ : partial pressure of oxygen $(\mathrm{mmHg}) ; B E e c f:$ base excess of extracellular fluid $(\mathrm{mmol} / \mathrm{L}) ; \mathrm{HCO}^{3}$ bicarbonate $(\mathrm{mmol} / \mathrm{L}) ; \mathrm{sO}^{2}:$ oxygen saturation (\%); $\mathrm{Na}+$ : sodium $(\mathrm{mmol} / \mathrm{L}) ;$ $K^{+}$: potassium (mmol/L); iCa ${ }^{2+}$ : ionized calcium (mmol/L); Glu: glucose (mg/dL); Hct: hematocrit (\% PCV); and Hbg: hemoglobin (g/dL).

Figure 5b. Transient Model

Venous blood paired samples T-Test in pre- and post- MCAO Sprague Dawley rats. 